This item was submitted to Loughborough's Research Repository by the author.

Items in Figshare are protected by copyright, with all rights reserved, unless otherwise indicated.

\title{
Comparison of centre of gravity and centre of pressure patterns in the golf swing
}

\section{PLEASE CITE THE PUBLISHED VERSION}

http://dx.doi.org/10.1080/17461391.2016.1240238

\section{PUBLISHER}

(C) European College of Sport Science

\section{VERSION}

AM (Accepted Manuscript)

\section{PUBLISHER STATEMENT}

This work is made available according to the conditions of the Creative Commons Attribution-NonCommercialNoDerivatives 4.0 International (CC BY-NC-ND 4.0) licence. Full details of this licence are available at: https://creativecommons.org/licenses/by-nc-nd/4.0/

\section{LICENCE}

CC BY-NC-ND 4.0

\section{REPOSITORY RECORD}

Smith, Aimee C., Jonathan R. Roberts, Pui W. Kong, and Stephanie E. Forrester. 2019. "Comparison of Centre of Gravity and Centre of Pressure Patterns in the Golf Swing". figshare.

https://hdl.handle.net/2134/23307. 


\title{
Comparison of centre of gravity and centre of pressure patterns inthe golf swing
}

\author{
AIMÉE C. SMITH ${ }^{1,2}$, JONATHAN R. ROBERTS ${ }^{1}$, PUI WAH KONG ${ }^{3}, \& \quad$ STEPHANIE
}

\section{E. FORRESTER ${ }^{1}$}

${ }^{1}$ Sports Technology Institute, Loughborough University, Loughborough, UK.

${ }^{2}$ Institute for Sports Research, Nanyang Technological University, Singapore, Singapore.

3Physical Education \& Sports Science Academic Group, National Institute of Education, Nanyang Technological University, Singapore, Singapore.

Keywords: Biomechanics, force plate, balance, principal component analysis, performance, golf

\begin{abstract}
Analysing the centre of pressure (COP) and centre of gravity (COG) could reveal stabilising strategies used by golfers throughout the golf swing. This study identified and compared golfers' COP and COG patterns throughout the golf swing in medial-lateral (ML) and anterior-posterior (AP) directions using principal component analysis (PCA) and examined their relationship to clubhead velocity. Three-dimensional marker trajectories were collected using Vicon motion analysis and force plate data from two Kistler force plates for 22 low-handicap golfers during drives. Golfers' COG and COP were expressed as a percentage distance between their feet. PCA was performed on COG and COP in ML and AP directions. Relationships between principal component (PC) scores were examined using Pearson correlation and regression analysis used to examine the relationship with clubhead velocity. ML COP movements varied in magnitude $\left(\mathrm{PC}_{1}\right)$, rate of change and timing $\left(\mathrm{PC}_{2}\right.$ and $\left.\mathrm{PC}_{3}\right)$. The COP and COG $\mathrm{PC}_{1}$ scores were strongly correlated in both directions (ML: $r=0.90, P<.05$; AP: $r=0.81, P<.05)$. Clubhead velocity, explained by three PCs $(74 \%)$, related to timing and rate of change in $\mathrm{COP}_{\mathrm{ML}}$ near downswing $\left(\mathrm{PC}_{2}\right.$ and $\left.\mathrm{PC}_{3}\right)$ and timing of $\mathrm{COG}_{\mathrm{ML}}$ late backswing $\left(\mathrm{PC}_{2}\right)$. The relationship between $\mathrm{COP}_{\mathrm{ML}}$ and $\mathrm{COG}_{\mathrm{ML}} \mathrm{PC}_{1}$ scores identified extremes of $\mathrm{COP}$ and $\mathrm{COG}$ patterns in golfers and could indicate a golfer's dynamic balance. Golfers with earlier movement of $\mathrm{COP}$ to the front foot $\left(\mathrm{PC}_{2}\right)$ and rate of change $\left(\mathrm{PC}_{3}\right)$ patterns in ML COP, prior to the downswing, may be more likely to generate higher clubhead velocity.
\end{abstract}

\section{Introduction}

Maintaining a balanced body position is critical instatic (e.g. standing) and dynamic situations (e.g. walking) to prevent falling, achieve the desired posture or movement (Hsue, Miller, \& Su, 2009; Winter, 1995). Golf coaches perceive golfers should remain balanced throughout the swing in order to maintain posture and produce accurate and powerful swings (Smith, Roberts, Wallace, Wah Kong, \& Forrester, 2015). In the golf biomechanics literature, a balanced body position has not been fully investigated but studying centre of pressure (COP) and centre of gravity (COG) could reveal stabilising strategies used by golfers to remain balanced throughout the swing. Whole body COG position in the global horizontal plane (Winter, 1995) has been used as a measure of overall body movement during balance studies (Caron, Gelat, Rougier, \& Blanch, 200o). COP position has been used as an indicator of the overall neuromuscular response to control the passive COG and restore equilibrium (Winter, 1995). The relationship between COG and COP revealed strategies for maintaining an upright posture during standing (Caron et al., 2000; Winter, 1995). In dynamic situations, the same strategy may not be indicative of instability and hence both measures should be investigated when analysing dynamic balance (Hsue et al., 2009). In this study, dynamic balance during the golf swing is explored by measuring COG and COP and is defined as a golfer's ability to remain balanced (i.e. not fall) whilst still achieving the intended outcome (i.e. generate high clubhead speed when striking the golf ball).

In the golf literature, more is known about COP patterns than COG (Ball \& Best, 2007a, 2007b, 2012; Barrentine, Fleisig, \& Johnson, 1994; Wallace, Grimshaw, \& Ashford, 1994). Group- based analyses have revealed two styles of COP movement in the medial-lateral (ML) direction for a heterogeneous group of golfers (Ball \& Best, 2007a, 2007b). The styles were termed "front foot" and "reverse foot" (Ball \& Best, 2007a, $2007 \mathrm{~b}$ ). For both styles, COP moves to the back foot 
(defined as the right foot of a right-handed golfer) during the backswing. The front foot style was characterised by COP translating towards the front foot (defined as the left foot for a right-handed golfer) during the downswing and through impact. The reverse group started moving forward in the early downswing before positioning the COP towards the back foot in the downswing, with COP positioned close to mid-stance at impact. There were no statistically significant differences in handicap or clubhead velocity when comparing the two styles. More recently, however, Ball and Best (2012) found significant relationships between COP measures and clubhead velocity on an individual golfer basis. Individualised golfer relationships between COP parameters and measures of performance could be due to the use of discrete measures which may not adequately represent the key features of the COP time-series. In addition, previous golf biomechanics research has defined discrete events in different ways, such as top of the backswing, making it difficult to compare across studies (Smith et al., 2015). Continuous data analysis techniques, such as principal component analysis (PCA), could overcome these limitations by identifying the key features of COP trajectories across the whole time-series. The PCA technique has been used to identify unique biomechanical movement strategies in sporting movements within groups of similar (Donà, Preatoni, Cobelli, Rodano, \& Harrison, 2009) and differing (Lynn, Noffal, Wu, \& Vandervoort, 2012) ability sportsmen.

Studies by Ball and Best (2007a, 2007b, 2012) used COP to investigate the coaching term "weight transfer". However, strictly COG rather than COP describes how a golfer's weight is distributed throughout the swing (Jenkins, 2008). The term "weight transfer" is often used by coaches to describe the observed weight under each foot of a golfer and does not serve as a biomechanical description. ML COG movement patterns were shown to be similar across all ability righthanded golfers in the backswing of a golf drive (Burden, Grimshaw, \& Wallace, 1998). During the downswing, differences in ML COG motion were observed and more linear patterns were associated with improved performance yet no direct comparisons were made to COP or measures of performance (Wrobel, Marclay, \& Najafi, 2012). Choi, Kang, and Mun (2016) furthered this finding by reporting that COG and COP separation could distinguish between golfing abilities and provided a valuable quantitative measure of a golfer's dynamic balance. Nevertheless, the study made no reference to individual golfer differences, analysed COG-COP during three distinct swing phases and also had no measure of performance.

The purpose of this study was to identify and compare golfers' COP and COG movement patterns throughout the golf swing in ML and anterior- posterior (AP) directions using PCA and identify relationships with measures of performance. The results could highlight different strategies employed by golfers to achieve dynamic balance during the golf swing and identify the key features of COP and COG movement patterns related to performance.

\section{Methods}

\section{Participants}

Twenty-two right-handed low-handicap golfers (handicap range +3 to 4 ; age $=26 \pm 7$ years; height $179.5 \pm 7.3 \mathrm{~cm}$; mass $=79.4 \pm 13.1 \mathrm{~kg}$ ) were recruited for the study. Golfers were either members of the University golf team or professional golfers from local clubs. All golfers gave their informed consent and ethical clearance was obtained from the University Ethical Advisory Committee.

\section{Data collection}

Testing took place in an indoor laboratory and threedimensional marker trajectories were collected using the Vicon Nexus Motion Analysis System (Oxford Metrics Ltd, UK) sampling at $250 \mathrm{~Hz}$. Sixty-three, $14 \mathrm{~mm}$ diameter retro-reflective markers were placed on each golfer at anatomical locations and four markers were placed on the golfer's own driver (Appendix 1). A piece of reflective tape was placed on the golf ball enabling the instant of impact to be ascertained.

Two force plates (Kistler, 9281CA), one under each foot of the golfer and synchronised with Vicon, collected ground reaction force data at $1000 \mathrm{~Hz}$. Two sections of golf mat, each equal in size to the force plates, were securely attached to the surface of the force plates. Before each trial a calibration procedure was carried out whereby a zero level of force was defined with only the golf mat in contact with the force plate.

Golfers wore their own golf shoes and glove and used the same brand golf ball (Titelist, ProVi). The golfers hit from the golf mat into a net positioned approximately four metres away; a vertical line was placed on the net to provide a target line. The global co-ordinate system (GCS) origin (o, o, o) was at ground level in the middle of the capture volume. The positive GCS axes were defined from the origin, with the $\mathrm{X}$-axis parallel to the target line but directed away from the target, the $\mathrm{Y}$-axis directed anteriorly and the Z-axis directed vertically upwards. A launch monitor (TrackMan, ISG Company, Denmark) gathered measures of performance. The launch monitor was positioned three metres in the direction of the GCS X-axis away from the ball and was positioned on the target line at the same height as the golf mat. A reflective dot was placed on the golf ball facing towards the launch monitor in accordance with the manufacturer's instructions.

After each golfer had performed their own warm up, golfers were instructed to address the ball in their normal stance position and to hit a full shot as accurately as possible (i.e. towards the target) with their driver. The golfer then performed 10 shots with their driver, with a one minute rest between shots. Following each shot, the golfer gave a subjective rating of shot 
quality on a 10-point scale (1-10) where the highest rating was considered representative of their best shot.

\section{Data analysis}

Five trials per golfer were analysed based on the quality of the data and high subjective ratings of shot quality. Marker positions were labelled using Vicon Nexus and further processing, including model building, were performed using Visual3D (C-motion Inc, USA). The golfer model comprised 16 segments (head, $2 \times$ upper arm, $2 \times$ lower arm, $2 \times$ hands, $2 \times$ thigh, $2 \times$ shank and $2 \times$ feet, trunk, pelvis and golf club). Whole body COG, was the estimated weighted sum of individual segments in accordance with Dempster's regression equations and the Hanavan model of the human body (Hanavan, 1964; Robertson, Caldwell, Hamill, Kamen, \& Whittlesey, 2014). Whole body COG was projected onto the laboratory floor global horizontal plane. The golf club was included in the COG determination, as had been done in previous studies of cricket batsmen (Taliep, Galal, \& Vaughan, 2007). For modelling purposes, golf club head weight was approximated at $0.20 \mathrm{~kg}$ and the shaft (including grip) as 0.15 $\mathrm{kg}$ which are within ranges stated for average club head and shaft weights in previous studies (Betzler, 2010; Harper, Roberts, \& Jones, 2005). The COG locations of the club head and shaft were estimated as midway between the club head heel and toe markers and mid-way between grip and hosel markers, respectively.

Force plate co-ordinate systems were transformed into the laboratory GCS and a global COP was computed from combining both force plates (Exell, Gittoes, Irwin, \& Kerwin, 2012). The COP and COG were defined along the $\mathrm{X}$-axis (ML) and Y-axis (AP) of the GCS. In the ML direction, $\mathrm{COP}_{\mathrm{ML}}$ and $\mathrm{COG}_{\mathrm{ML}}$ were defined as a percentage of the distance between the $\mathrm{X}$-coordinates of the mid-point of the front (o\%) and back (100\%) foot at set-up. In the AP direction, $\mathrm{COP}_{\mathrm{AP}}$ and $\mathrm{COG}_{\mathrm{AP}}$ were defined as a percentage distance between the $\mathrm{Y}$ coordinates of the furthest back heel (o\%) and furthest forward toe (100\%) markers of the front and back foot at set-up. Each swing was temporally aligned between take-away (TA) to top of the backswing (TB), TB to impact (IMP) and IMP to mid-follow through (MidFT) using a piecewise linear length normalisation procedure (Helwig, Hong, Hsaio-Wecksler, \& Polk, 2011) to 501 normalised time points. The phases of the golf swing were defined using the following threshold functions in Visual3D: TA when the X-component of velocity of the clubhead heel marker (i.e. horizontal velocity in the GCS X-axis direction) first exceeded $0.2 \mathrm{~ms}^{-1}$; TB when the X-component of velocity of the clubhead heel marker changed from negative to positive; IMP as the time point immediately preceding the frame where ball positional data changed; MidFT when the club shaft (defined as a vector between a marker on the grip and hosel) was parallel to the GCS X-axis. Between TA and TB there were 410 normalised time points, TB and IMP there were 70 time normalised time points, and IMP and MidFT there were 21 normalised time points.

\section{Statistical analysis}

In this study, it was of interest to determine the extent of inter-golfer variation in COP and COG timeseries data in ML and AP directions throughout the swing. As such, for each golfer, an $n \times p$ data matrix was formed where $\mathrm{n}$ was the number of trials $(n=5)$ and $p$ each normalised time point throughout the swing $(p=501)$. This was done for each variable $\left(\mathrm{COP}_{\mathrm{ML}}, \mathrm{COG}_{\mathrm{ML}}, \mathrm{COP}_{\mathrm{AP}}\right.$ and $\left.\mathrm{COG}_{\mathrm{AP}}\right)$.

Matrices for each golfer were then vertically concatenated to form a single $110 \times 501$ data matrix representing all the golfers' data for a given variable. This matrix was used as input to the PCA MATLAB function (MATLAB, The Mathworks, Natick, MA). A maximum number of 109 PCs were computed; however only PCs which cumulatively explained at least 90\% of the variance were retained for further analysis (Deluzio \& Astephen, 2007; Lynn et al., 2012).

Principle component analysis (PCA) generates a series of principal components $\left(\mathrm{PC}_{1}, \mathrm{PC}_{2}\right.$, and $\left.\mathrm{PC}_{3} \ldots\right)$, each explaining a percentage of the variation in the original data. Each PC is defined by a loading factor, a series of positive or negative values which indicate the magnitude and direction of variation in movement patterns relative to the mean data curve at every time increment. A loading factor therefore contains the same number of data points as the original data and the larger the loading factor the greater the variability in the data. A loading factor close to zero contributes little to the PC and indicates that there was little difference in the movement patterns at that stage in the swing. PCA also computes a score for each data set, in this case for each trial by every golfer, for each PC. A large positive (+ve) or negative (-ve) PC score indicates a golfer whose data curve for that trial is further away from the mean curve in the portions of the swing that have higher loading factors. The sign of the PC score, in tandem with the sign of the loading factor, dictates the direction of change from the mean curve.

Qualitative biomechanical interpretation of PCs was achieved by examining the loading factors for each $\mathrm{PC}$ and observing the mean data curves of COP and COG with plus and minus one standard deviation of PC scores multiplied by the loading factor for each PC (Figures 1-3).

Pearson's correlation was performed to examine the relationship between COP and COG PC scores in ML and AP directions with significance set at $P<.05$. The strength of the correlation coefficients $(r)$ were categorised as follows: weak (less than 0.4 ), moderate (0.41 to 0.7) and strong (0.71 to 1) (Dancey \& Reidy, 2011).

A stepwise mixed-effects linear regression model (backward elimination) with individual golfer as a random effect was fitted to clubhead velocity (dependent variable) and standardised PC scores (explanatory variables) to predict whether any of the PCs could explain variation in clubhead velocity. 


\section{Results}

\section{COP and COG movement patterns}

A greater number of PCs were required to explain 90\% of the variance in COP parameters (4-5 PCs) compared to COG (2 PCs) parameters (Table I). The biomechanical interpretation of PCs largely related to an offset (i.e. magnitude), timing, rate of change and range in a given parameter (Table I).

Mean curves with plus or minus one standard deviation of the PC score multiplied by the loading factor helped interpret the movement patterns of golfers with either positive or negative PC scores for a specific PC (Robertson et al., 2014) (Figures 1 and 2). The mean curves are colour coded according to the loading factors for that PC. The description of golfers with +ve or -ve PC scores are provided in Table I and also graphically shown in Figures 1 and 2.

\section{Relationship between COP and COG principal Components}

The only two strong correlations were between $\mathrm{COG}_{\mathrm{ML}}$ and $\mathrm{COP}_{\mathrm{ML}} \mathrm{PC} 1$ scores $(i=0.92, P<.05)$ and $\mathrm{COP}_{\mathrm{AP}}$ and $\mathrm{COG}_{\mathrm{AP}} \mathrm{PC} 1$ scores $(r=0.81, P<.05)$ (Figure $3(\mathrm{a})$ and $3(\mathrm{~b}))$. For brevity only the relationship between $\mathrm{COG}_{\mathrm{ML}}$ and $\mathrm{COP}_{\mathrm{ML}}$ will be presented and is explored in greater detail in Figure $3(\mathrm{c})-3(\mathrm{f})$. Golfer 7 and Golfer 8 were chosen to explore the relationship between $\mathrm{COG}_{\mathrm{ML}}$ and $\mathrm{COP}_{\mathrm{ML}} \mathrm{PC}_{1}$ scores as they had opposing scores (Figure 3(a)). Golfer 7 had low negative $\mathrm{COG}_{\mathrm{ML}}$ and $\mathrm{COP}_{\mathrm{ML}} \mathrm{PC} 1$ scores. The PC score relationship for this golfer showed that in the backswing, there was greater movement of $\mathrm{COG}_{\mathrm{ML}}$ to the back foot coupled with a greater range in $\mathrm{COP}_{\mathrm{ML}}$ to the back foot whereby $\mathrm{COP}_{\mathrm{ML}}$ moved beyond the $\mathrm{COG}_{\mathrm{ML}}$ position. At IMP, $\mathrm{COG}_{\mathrm{ML}}$ was closer to mid-stance $(\sim 50 \%)$ and was coupled with a reversal of $\mathrm{COP}_{\mathrm{ML}}$ from front foot to back foot during the downswing (Figure 3(c) and 3(e)). Golfer 8 had high positive $\mathrm{COG}_{\mathrm{ML}}$ and $C O \mathrm{P}_{\mathrm{ML}}$ $\mathrm{PC}_{1}$ scores. This relationship showed that less movement of the $\mathrm{COG}_{\mathrm{ML}}$ towards the back foot was coupled with less movement of the $\mathrm{COP}_{\mathrm{ML}}$ onto the back foot and $\mathrm{COP}_{\mathrm{ML}}$ moved beyond $\mathrm{COG}_{\mathrm{ML}}$. During the downswing, the $\mathrm{COG}_{\mathrm{ML}}$ continued to move towards the front foot and was coupled with greater movement of the $\mathrm{COP}_{\mathrm{ML}}$ ahead of $\mathrm{COG}_{\mathrm{ML}}$ and towards the front foot.

\section{Relationship between COP, COG principal components and clubhead velocity}

The overall mean clubhead velocity across all golfers, measured by TrackMan, was $45.46 \pm 2.54 \mathrm{~ms}^{-1}$. From the regression analysis of the predictor PCs, three were significant and predicted $74 \%$ of the variance in clubhead velocity (adjusted $r^{2}=0.742, P<.001$ ). The most important predictor of clubhead velocity was $\mathrm{COP}_{\mathrm{ML}}$ $\mathrm{PC}_{3}\left(\beta=0.449, s_{x_{-}}=0.186, P<.05\right)$ and would give the greatest increase (relative to standard deviation) in clubhead velocity. Golfers whose COP was closer to their back foot in the mid-backswing would have higher clubhead velocities. The second most important predictor was $\mathrm{COG}_{\mathrm{ML}} \mathrm{PC} 2\left(\beta=-0.399, s_{x-}=0.201, P<\right.$ .05); however this would decrease clubhead velocity. Hence, golfers with early COG movement towards the front foot before TB would have lower clubhead velocity. Lastly, $\mathrm{COP}_{\mathrm{ML}} \mathrm{PC}_{2}\left(\beta=0.323, s_{x_{-}}=0.156, P<.05\right)$ would increase clubhead velocity (relative to standard deviation). Hence, golfers with early movement of COP to front foot in back- swing would have higher clubhead velocity. Neither the PC scores in AP direction nor the PC1 scores in the ML direction appeared to be significant predictors of clubhead velocity.

\section{Discussion}

The purpose of this study was to identify and compare golfers' COP and COG movement patterns throughout the golf swing in $\mathrm{ML}$ and AP directions using PCA and examine the relationship with measures of performance.

Movement patterns represented by positive and negative $\mathrm{COP}_{\mathrm{ML}} \mathrm{PC}_{1}$ scores resembled the front foot and reverse foot styles, respectively, reported by Ball and Best (2007a, 2007b). This result confirms the identification of two extremes of ML COP movement, for a group of similar ability golfers (Figure 3 ).

Golfers, however, featured on a continuum between these two extremes as can be seen by the spread in $\mathrm{PC}_{1}$ scores on the scatterplot in Figure 3(a) and cannot be categorised clearly into either of these extreme styles. The timing and rate of change in $\mathrm{COP}_{\mathrm{ML}}\left(\mathrm{PC}_{2}\right.$ and $\left.\mathrm{PC}_{3}\right)$ in the backswing and down- swing were also key features of $\mathrm{COP}_{\mathrm{ML}}$ (Table I). Previous studies have found significant correlations between clubhead velocity and the velocity of $\mathrm{COP}_{\mathrm{ML}}$ at discrete stages in the early downswing or late backswing (Ball \& Best, 2012). The benefits of the PCA approach used in this study are that PCs capture these key features (variances) wherever they occur during the swing. These can subsequently be used to investigate relationships with performance measures (such as in clubhead velocity presented herein) or with other kinematic/kinetic v a r i ables. 
(a) $\quad \mathrm{COP}_{\mathrm{ML}} \mathrm{PCl}$

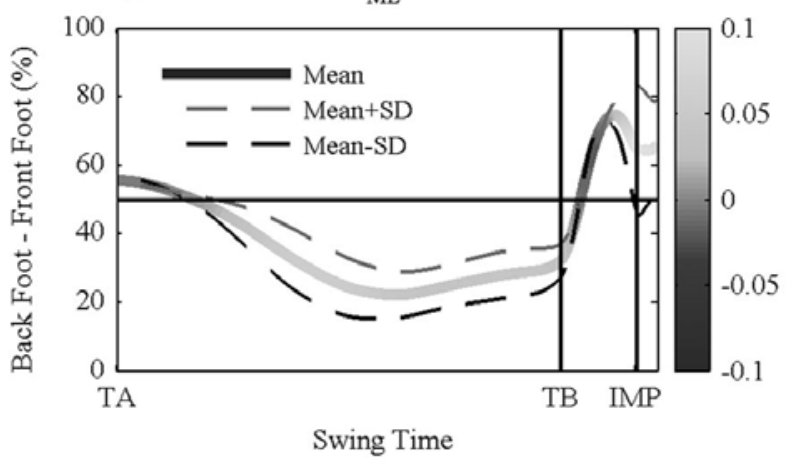

(c)

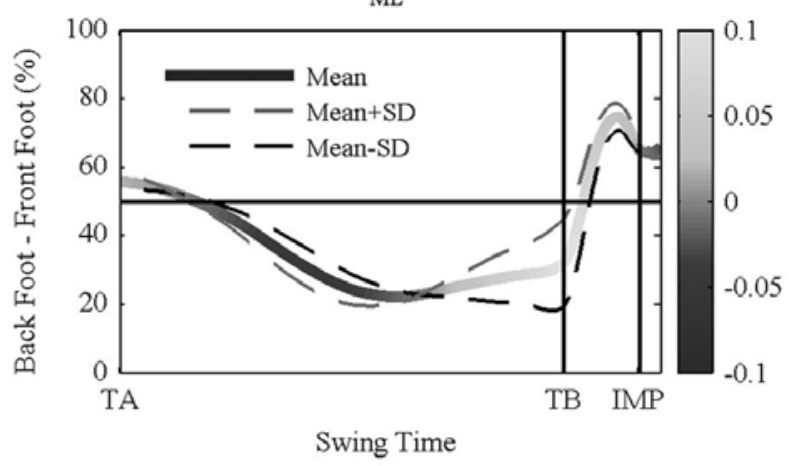

(e)

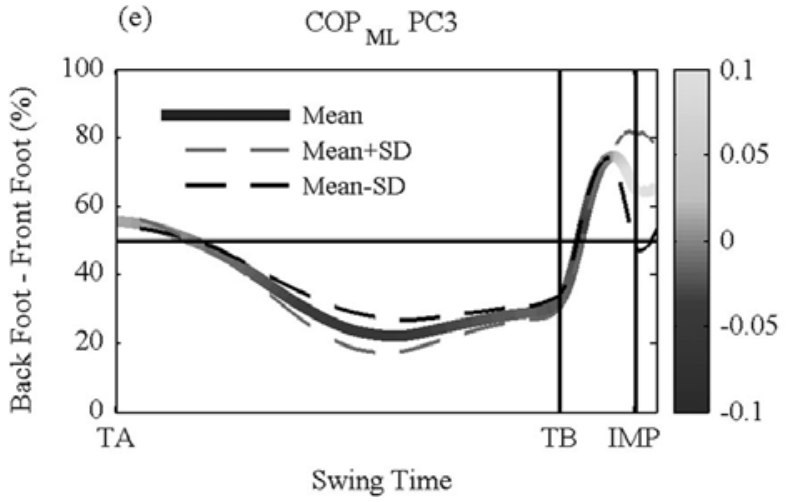

(b) $\quad \mathrm{COP}_{\mathrm{AP}} \mathrm{PCl}$

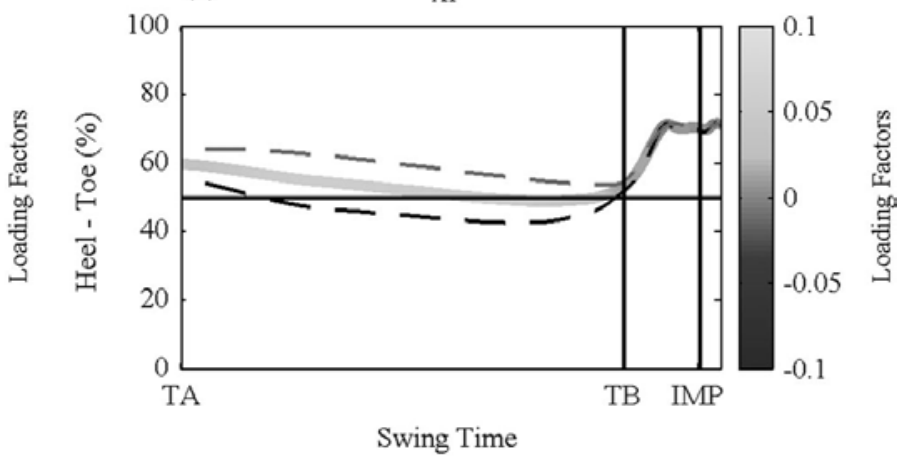

(d)
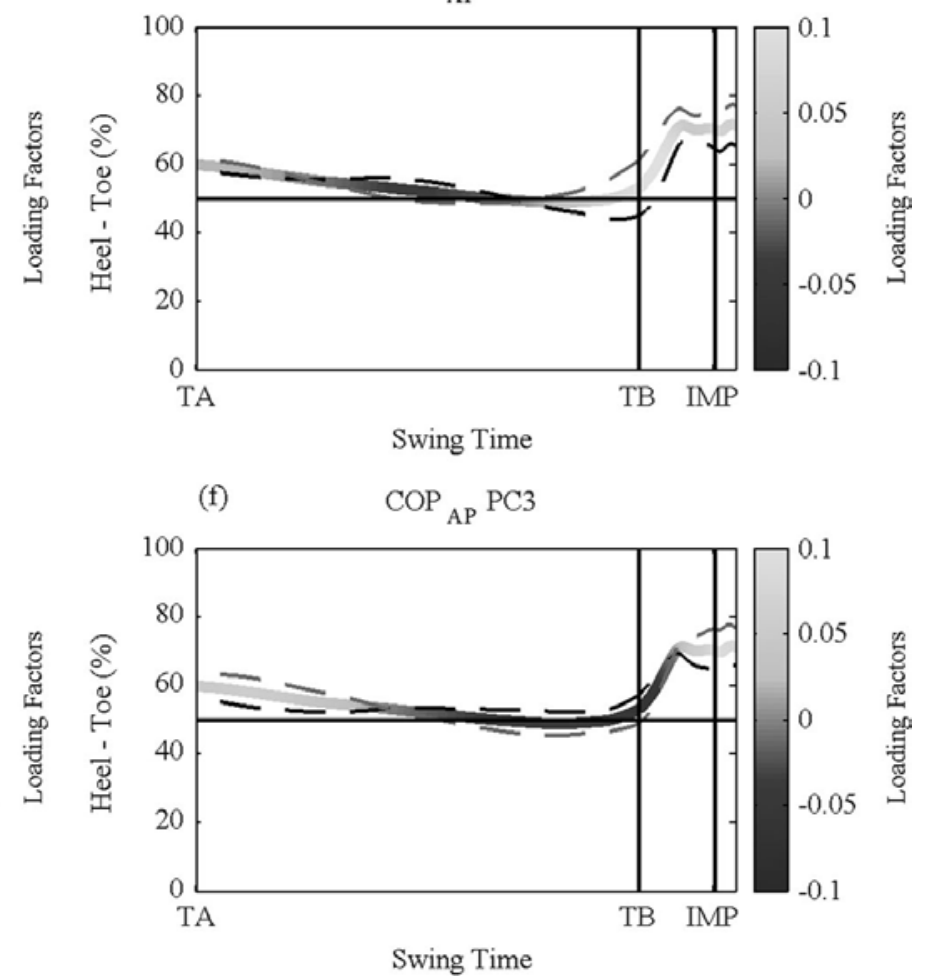

Figure 1. Mean curve (colour graded by PC loading factor) \pm one SD of PC scores multiplied by loading factors for COPML and COPAP (a and b), PC1 (c and d), PC2 and (e and f) PC 3 , respectively. Golfers with PC scores of mean + one SD followed dashed grey line and those with PC scores of mean - one SD followed the dashed black line. 
(a)

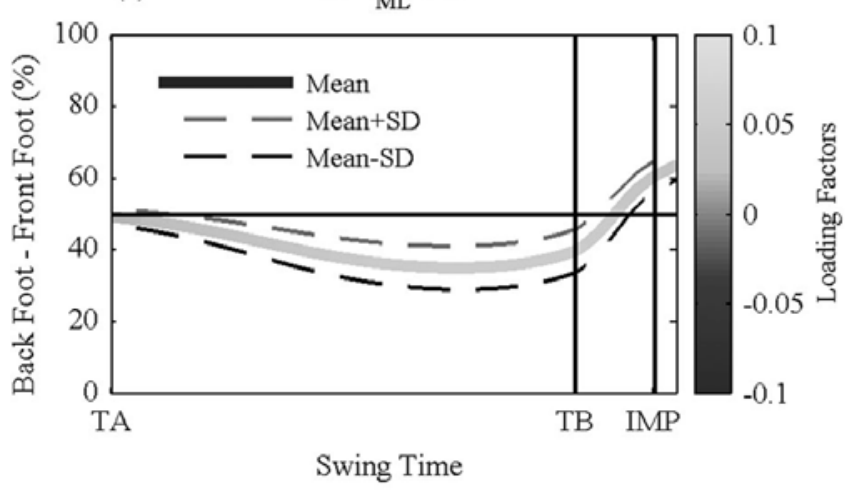

(c)

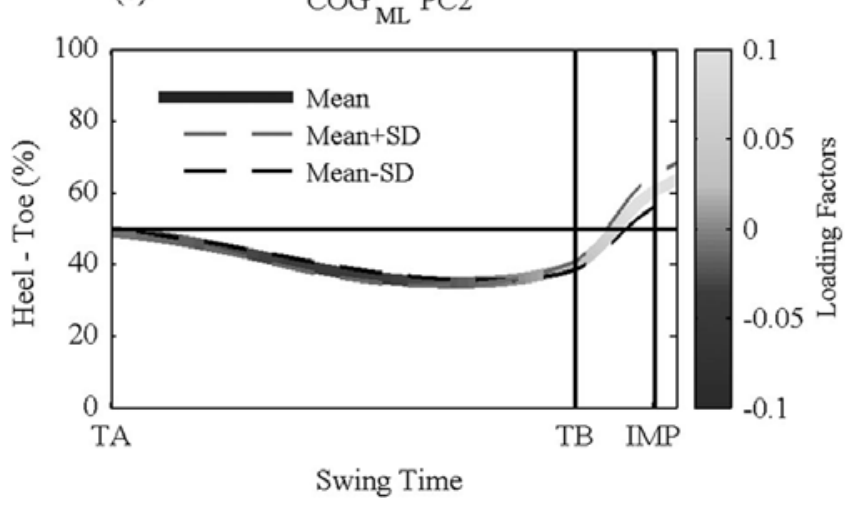

(b)

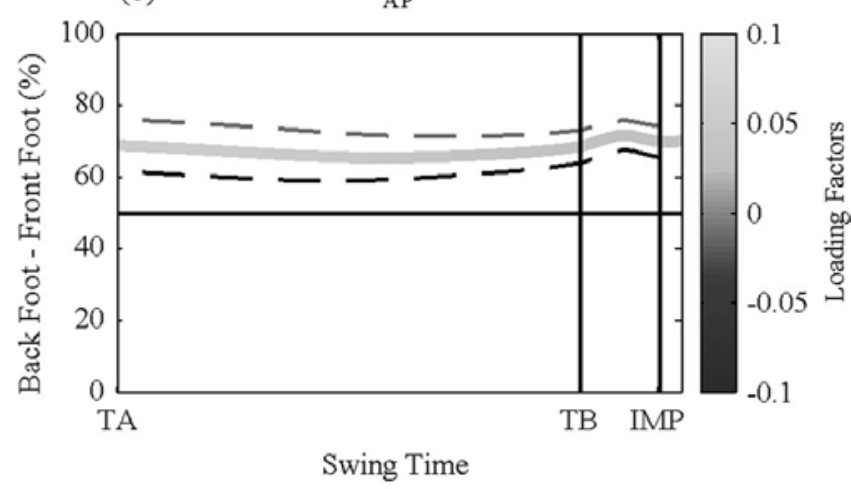

(d)

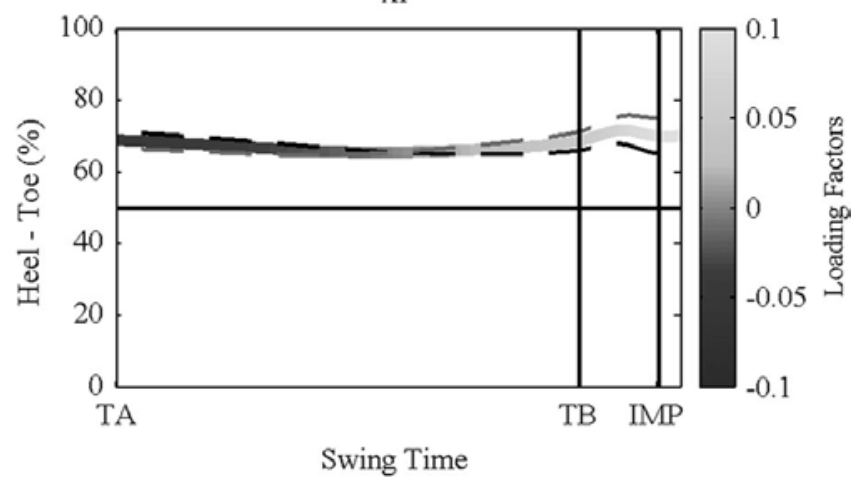

Figure 2. Mean curve (colour graded by PC loading factor) \pm one SD of PC scores multiplied by loading factors for $\mathrm{COG}_{\mathrm{ML}}$ and $\mathrm{COG}_{\mathrm{AP}}$ ( $\mathrm{a}$ and b) PC1 and (c and d) PC2, respectively. Golfers with PC scores of mean + one SD followed dashed grey line and those with PC scores of mean - one SD followed the dashed black line.

Eighty-four per cent of variance was explained by $\mathrm{COG}_{\mathrm{ML}} \mathrm{PC}_{1}$ and described the position of $\mathrm{COG}$ throughout the swing. The ML COG pattern captured by $\mathrm{PC}_{1}$ is similar to the pattern described by Burden et al. (1998) and the distinguishing difference between high- and low-handicap golfers captured using the methods of Choi et al. (2016). Examining the strong linear relationship $(r=0.92)$ between $C O P$ and $C^{-O G} G_{M L}$ $\mathrm{PC}_{1}$ scores in this study can help to understand this movement pattern further (Figure $3(\mathrm{a})$ ). At TA, COG $\mathrm{CL}_{\mathrm{ML}}$ is evenly positioned between front and back foot before moving towards the back foot and as such COP moves beyond the COG position (i.e. closer to the back foot). During the downswing, the COP begins to move ahead of the COG towards the front foot and the extreme styles see golfers either align COP and COG at impact (-ve PC1 scores) or COP stays ahead of the COG and both are closer to the front foot (+ve $\mathrm{PC}_{1}$ scores) at IMP. Welch, Banks, Cook, and Draovitch (1995) reported the interaction of ML COP and COG in baseball hitters as a measure of dynamic balance. Baseball hitters who aligned COP and COG evenly between the feet near impact emphasised rotational body movements, whereas hitters with COG and COP to- wards the front foot emphasised more linear body movement. The rotational movements and alignment of COP and COG were deemed to increase the force couple applied to the pelvis and facilitate pelvis rotational acceleration whereas linear movement meant force was only applied through the front foot when striking the baseball (Welch et al., 1995). Given the outcome of a baseball swing is also to strike the ball as far as possible it is interesting to note the similarities between the results of this study and those of Welch et al. (1995). Therefore, it would also be of interest to compare a golfer's body rotation variables to their COP and $\mathrm{COG}$. 
(a)

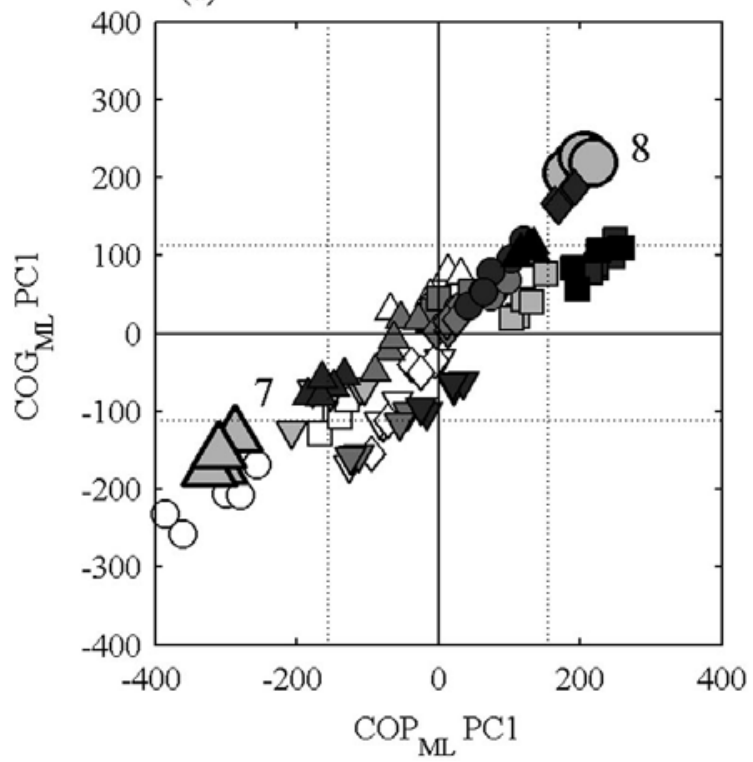

(c)

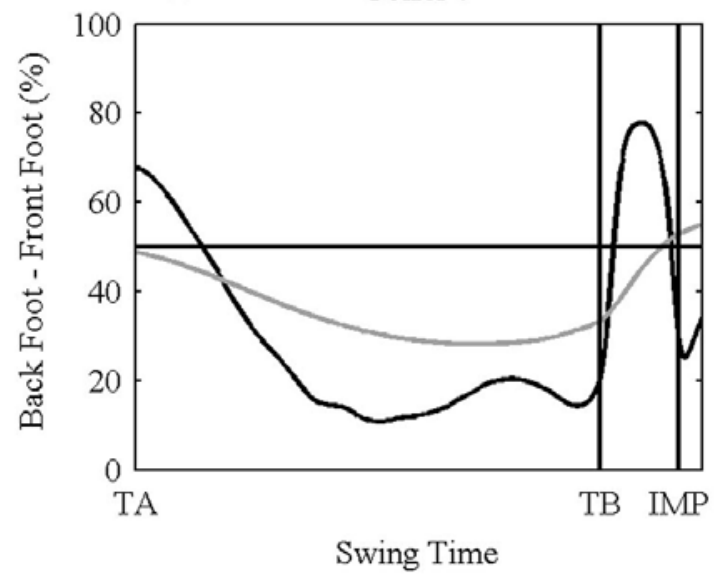

(e)

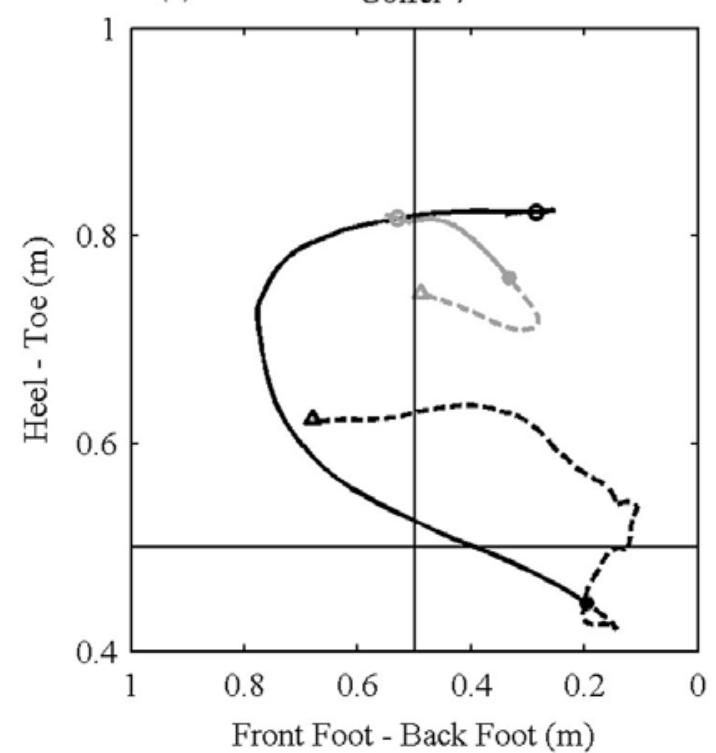

(b)

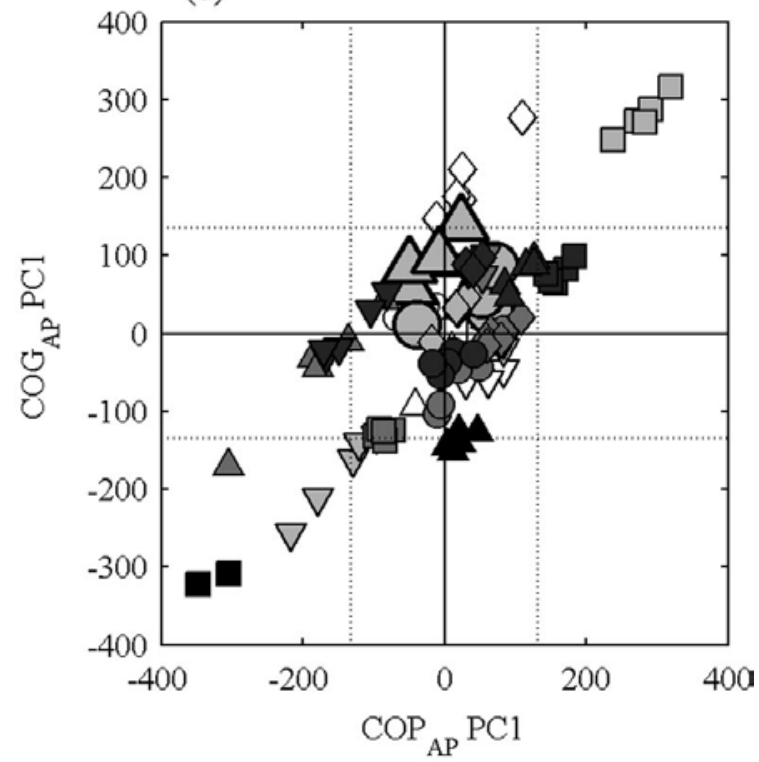

(d)

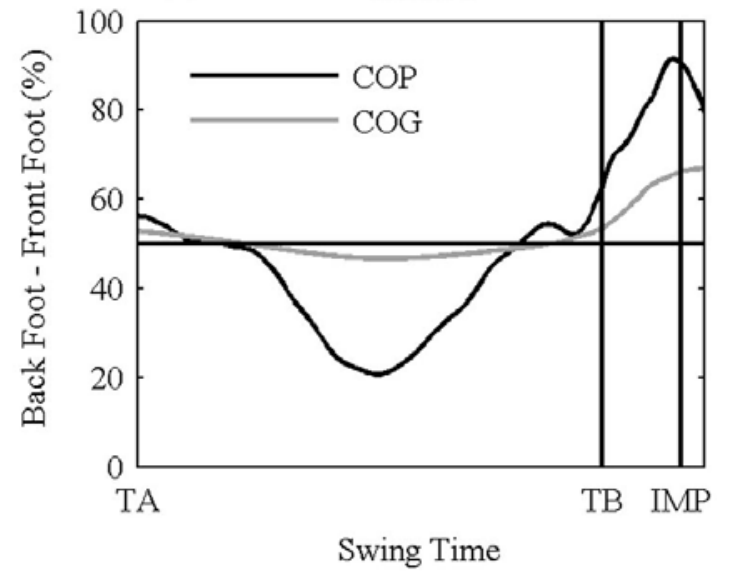

(f)

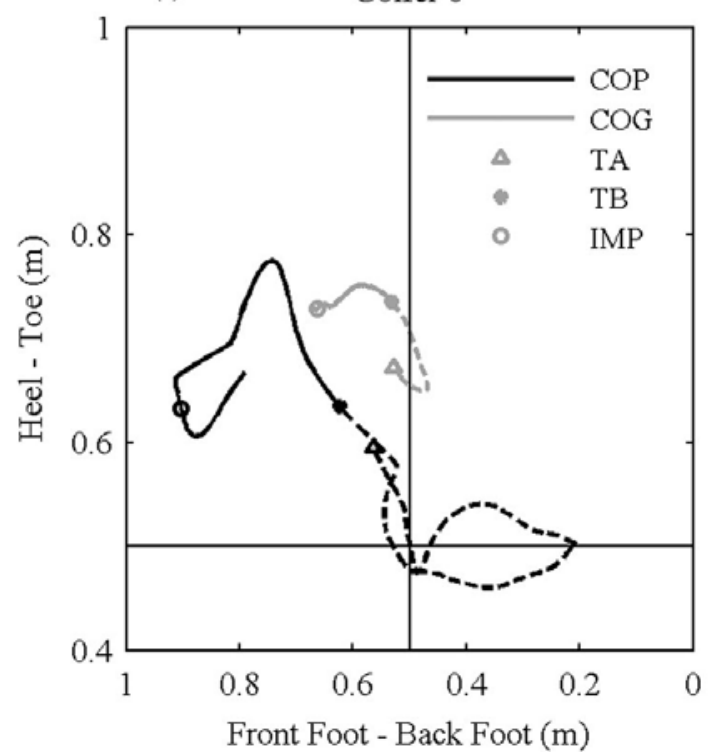

Figure 3. Scatterplot of $\mathrm{PC}_{1}$ scores for (a) $\mathrm{COG}_{\mathrm{ML}}$ and $\mathrm{COP}_{\mathrm{ML}}$ and (b) $\mathrm{COP}_{\mathrm{AP}}$ and $\mathrm{COG}_{\mathrm{AP}}$. Dashed lines represent one SD of the PC scores (c) COP and COG overall movement traces for Golfer 7 and (d) Golfer 8, (e) Golfer 7 ML COP and COG trajectories and (f) Golfer 8 ML COP and COG trajectories. 
Table I. Percentage variance explained (\%), general biomechanical interpretation of COP and COG principal components (PCs) and positive and negative PC scores in medial-lateral (ML) and anterior-posterior (AP) directions throughout the swing. $\mathrm{TB}=$ top of the backswing, $\mathrm{IMP}=$ impact, $\mathrm{TA}=$ takeaway.

\begin{tabular}{|c|c|c|c|c|c|}
\hline Parameter & $\mathrm{PC}$ & $\%$ & $\begin{array}{l}\text { Biomechanical } \\
\text { Interpretation }\end{array}$ & Positive PC Score & Negative PC Score \\
\hline \multirow[t]{5}{*}{$\mathrm{COP}_{\mathrm{ML}}$} & 1 & 37.8 & $\begin{array}{l}\text { Position TA to TB and } \\
\text { rate of change and direc- } \\
\text { tion TB to IMP }\end{array}$ & $\begin{array}{l}\text { Less movement to back foot } \\
\text { between TA to TB. Closer } \\
\text { to front foot at IMP }\end{array}$ & $\begin{array}{l}\text { More movement to back foot } \\
\text { TA to TB. Movement to front } \\
\text { foot near TB, rapid movement } \\
\text { to mid stance before IMP }\end{array}$ \\
\hline & 2 & 22.5 & $\begin{array}{l}\text { Timing and position from } \\
\text { TA to TB and rate of } \\
\text { change TB to IMP }\end{array}$ & $\begin{array}{l}\text { Early movement to back foot } \\
\text { TA to mid-backswing, } \\
\text { movement towards front foot } \\
\text { mid-backswing to mid- } \\
\text { downswing }\end{array}$ & $\begin{array}{l}\text { Late movement to back foot } \\
\text { and rapid movement towards } \\
\text { front foot near TB }\end{array}$ \\
\hline & 3 & 18.0 & $\begin{array}{l}\text { Position mid-backswing } \\
\text { and rate of change and di- } \\
\text { rection from mid- } \\
\text { downswing to IMP }\end{array}$ & $\begin{array}{l}\text { Position closer to back foot } \\
\text { mid-backswing. Rapid } \\
\text { movement to front foot TB } \\
\text { to IMP }\end{array}$ & $\begin{array}{l}\text { Position closer to front foot at } \\
\text { mid-backswing, movement to } \\
\text { front foot near TB before } \\
\text { movement to mid stance be- } \\
\text { fore IMP }\end{array}$ \\
\hline & 4 & 6.8 & $\begin{array}{l}\text { Range of COP in back- } \\
\text { swing and rate of COP to } \\
\text { front foot before TB }\end{array}$ & $\begin{array}{l}\text { Greater movement towards } \\
\text { back foot mid-way between } \\
\text { TA to TB early movement } \\
\text { to front before TB }\end{array}$ & $\begin{array}{l}\text { Less movement towards back } \\
\text { foot mid-way between TA to } \\
\text { TB late movement to front } \\
\text { before TB }\end{array}$ \\
\hline & 5 & 5.6 & $\begin{array}{l}\text { Rate of COP to front foot } \\
\text { before TB and through } \\
\text { IMP }\end{array}$ & - & - \\
\hline \multirow[t]{4}{*}{$\mathrm{COP}_{\mathrm{AP}}$} & 1 & 46.1 & $\begin{array}{l}\text { Position between TA to } \\
\text { TB and timing before TB }\end{array}$ & $\begin{array}{l}\text { Position towards heels be- } \\
\text { tween TA to TB. Late } \\
\text { movement towards toes }\end{array}$ & $\begin{array}{l}\text { Position towards toes TA to } \\
\text { TB. Early movement to toes } \\
\text { before TB }\end{array}$ \\
\hline & 2 & 18.0 & $\begin{array}{l}\text { Timing and rate of change } \\
\text { towards toes before TB to } \\
\text { IMP }\end{array}$ & $\begin{array}{l}\text { Early and gradual movement } \\
\text { towards toes before TB and } \\
\text { closer to toes at IMP }\end{array}$ & $\begin{array}{l}\text { Late and rapid movement to- } \\
\text { wards toes near TB and closer } \\
\text { to heels at IMP }\end{array}$ \\
\hline & 3 & 14.8 & $\begin{array}{l}\text { Timing and rate of change } \\
\text { towards heels from TA to } \\
\text { TB and position at IMP }\end{array}$ & $\begin{array}{l}\text { Greater movement from toes } \\
\text { to heels in backswing and } \\
\text { closer to toes at IMP }\end{array}$ & $\begin{array}{l}\text { Stable position until near TB } \\
\text { and less shift towards toes at } \\
\text { IMP }\end{array}$ \\
\hline & 4 & 11.4 & $\begin{array}{l}\text { Position in backswing and } \\
\text { rate of change towards } \\
\text { toes before IMP }\end{array}$ & - & - \\
\hline \multirow[t]{2}{*}{$\mathrm{COG}_{\mathrm{ML}}$} & 1 & 83.8 & Position throughout swing & $\begin{array}{l}\text { Less movement towards } \\
\text { back foot in backswing and } \\
\text { closer to front foot at IMP }\end{array}$ & $\begin{array}{l}\text { More movement towards } \\
\text { back foot in backswing and } \\
\text { closer to mid-stance at IMP }\end{array}$ \\
\hline & 2 & 10.4 & $\begin{array}{l}\text { Timing towards front foot } \\
\text { before TB and position } \\
\text { between TB to IMP }\end{array}$ & $\begin{array}{l}\text { Early movement to front foot } \\
\text { before TB and closer to front } \\
\text { foot at IMP }\end{array}$ & $\begin{array}{l}\text { Late movement to front foot } \\
\text { after TB and closer to mid } \\
\text { foot at IMP }\end{array}$ \\
\hline \multirow[t]{2}{*}{$\mathrm{COG}_{\mathrm{AP}}$} & 1 & 83.5 & Position throughout swing & $\begin{array}{l}\text { Nearer toes. In downswing, } \\
\text { shifted slightly towards heels } \\
\text { before movement to toes }\end{array}$ & $\begin{array}{l}\text { Further towards heels. In } \\
\text { downswing, shifted slightly } \\
\text { towards heels before move- } \\
\text { ment to toes }\end{array}$ \\
\hline & 2 & 12.1 & $\begin{array}{l}\text { Timing of movement be- } \\
\text { tween TA and TB and po- } \\
\text { sition between TB - IMP }\end{array}$ & $\begin{array}{l}\mathrm{COG}_{\mathrm{AP}} \text { positioned towards } \\
\text { toes mid-backswing and near } \\
\text { toes between TB and IMP }\end{array}$ & $\begin{array}{l}\mathrm{COG}_{\mathrm{AP}} \text { positioned towards } \\
\text { heels mid-backswing and } \\
\text { closer to mid foot between } \\
\text { TB and IMP }\end{array}$ \\
\hline
\end{tabular}


Golfers typically positioned $\mathrm{COP}_{\mathrm{AP}}$ closer to the toes at TA $(\sim 60 \%)$ before a slight shift to the heels in the backswing, moving towards the toes in the downswing and remaining relatively stable through IMP (Figure 1(b)). The movement pattern varied in magnitude in the backswing $\left(\mathrm{PC}_{1}\right)$, timing of $\mathrm{COP}_{\mathrm{AP}}$ movement before $\mathrm{TB}$ $\left(\mathrm{PC}_{2}\right)$ and range of $\mathrm{COP}_{\mathrm{AP}}$ movement in the late backswing to early downswing $\left(\mathrm{PC}_{3}\right)$. Lynn et al. (2012) reported similar timings of peak vertical and peak posterior force in early downswing differentiated high- and low-skilled golfers and was thought to help create a force couple to facilitate body rotation. Whilst the measures used in this study are not directly comparable to Lynn et al.'s (2012) study, there is evidence to support that the timing of AP COP (PC2 scores) can also distinguish between golfers of similar ability and hence may be used to identify strengths or weaknesses in golfers movement patterns. In the downswing, there was a small shift in $\mathrm{COG}_{\mathrm{AP}}$ movement which varied in magnitude ( $\mathrm{PC}_{1}$ and $\mathrm{PC}_{2}$ ) (Figure 2(b) and 2(d)). This COG movement may indicate a golfer's ability to react to the high forces of the club (radial and centripetal) before impact (Hellström, 2009) and PC scores could identify golfers who can reasonably do this. The relationship between AP COP and COG PC1 $(r=0.81)$ scores shows that the small shift in $\mathrm{COG}_{\mathrm{AP}}$ during the downswing (Figure 2(b)) coincides with a relatively stable period in $\mathrm{COP}_{\mathrm{AP}}$ (Figure $1(\mathrm{~b})$ ). This relationship may further suggest that at this swing instance, the greatest requirement is to resist the large club forces rather than generate forces to create body rotation.

From regression analysis, $74 \%$ of clubhead velocity was explained by three PCs. The range in $\mathrm{COP}_{\mathrm{ML}}$ in the backswing and rate of change in $\mathrm{COP}_{\mathrm{ML}}$ in the downswing $\left(\mathrm{PC}_{3}\right)$ were the greatest predictors of clubhead velocity. Ball and Best (2012) found that a larger mediolateral COP velocity at early downswing was an important predictor of clubhead velocity for some golfers. The results of this study would support the coaching notion that increasing the rate of $\mathrm{COP}_{\mathrm{ML}}$ towards the front foot during early downswing could increase clubhead velocity (Jenkins, 2008). A more positive $\mathrm{COP}_{\mathrm{ML}}$ $\mathrm{PC}_{2}$ score (i.e. early movement of COP to front foot in backswing) was positively related to clubhead velocity. This finding is similar to Lynn et al.'s (2012) PCA results where they observed early unloading of vertical force under the back foot in the backswing of highly skilled golfers. The authors concluded that early movement of vertical force onto the front foot was more effective in allowing the sequence of body rotations. Conversely, early COG movement towards the front foot (+ve $\mathrm{COG}_{\mathrm{ML}} \mathrm{PC}_{2}$ ) was found to decrease clubhead velocity. This finding could relate to Lynn et al.'s (2012) study that found the timing and direction of ground reaction forces was a key feature of highly skilled golfers. Force couples that encourage too early lateral movement of COG could hinder generation of clubhead velocity. Whilst there is a strong relationship between COP and COG PC1 scores neither were significant predictors of clubhead velocity. Interestingly Golfer 7 and Golfer 8, with opposing PC1 scores, had similar average clubhead velocity $\left(49.6 \pm 0.5 \mathrm{~ms}^{-1}\right.$ and $48.4 \pm 0.6 \mathrm{~ms}^{-1}$, respectively) and were both approximately $3 \mathrm{~ms}^{-1}$ quicker than the overall average across all golfers. Similarly, AP PCs were also not related to clubhead velocity. As coaches also stated that dynamic balance could affect accuracy (Smith et al., 2015), future studies should investigate the relationship between COP and COG PCs and other measures of performance related to shot accuracy.

In conclusion, this study used PCA and showed the greatest variation in COP movement patterns in ML and AP directions was related to magnitude, timing and rate of change throughout the golf swing. The golfers' COG movement patterns were relatively similar in shape and typically differed in magnitude or timing of movement. The relationship between $\mathrm{COP}_{\mathrm{ML}}$ and $\mathrm{COG}_{\mathrm{ML}} \mathrm{PC}_{1}$ scores identified different extremes of COP and COG movement in golfers and could be an indication of how golfers achieve dynamic balance either with more lateral or rotational movement. Golfers displaying early movement of ML COP to the front foot in the backswing ( $\mathrm{PC}_{2}$ ) or greater range and rate of movement to the front foot in the downswing ( $\left.\mathrm{PC}_{3}\right)$ were more likely to have higher clubhead velocity. Golfers that moved their COG towards the front foot earlier in the backswing, however, were more likely to have lower clubhead velocity. Future studies using PCA should investigate the relationships between these PCs, golfer kinematic variables and other measures of performance. 


\section{References}

Ball, K., \& Best, R. (2007a). Different centre of pressure patterns within the golf stroke I: Cluster analysis. Journal of Sports Sciences, 25(7), 757-770. Retrieved from http://www.ncbi.nlm. nih.gov/pubmed/17454544

Ball, K., \& Best, R. (2007b). Different centre of pressure patterns within the golf stroke II: Group-based analysis. Journal of Sports Sciences, 25(7), 771-779. Retrieved from http://www.ncbi.nlm. nih.gov/pubmed/17454545

Ball, K., \& Best, R. (2012). Centre of pressure patterns in the golf swing: Individual-based analysis. Sports Biomechanics, 11(2), 175-189. Retrieved from http://www.ncbi.nlm.nih.gov/ pubmed/22900399

Barrentine, S., Fleisig, G., \& Johnson, H. (1994). Ground reaction forces and torques of professional and amateur golfers. Paper pre- sented at the meeting of World Scientific Congress of Golf, Scotland.

Betzler, N. (2010). The effect of differing shaft dynamics on the biome-chanics of the golf swing (Unpublsihed doctoral dissertation). University of Ulster, N.Ireland.

Burden, A., Grimshaw, P., \& Wallace, E. (1998). Hip and shoulder rotations during the golf swing of sub-10 handicap players. Journal of Sports Sciences, 16(2), 165-176. Retrieved from http://www.ncbi.nlm.nih.gov/pubmed/9531005

Caron, O., Gelat, T., Rougier, P., \& Blanch, T.-P. (2000). A com- parative analysis of centre of grvaity and centre of pressure tra- jectory path lengths in standing posture: An estimation of active stiffness. Journal of Applied Biomechanics, 16, 234-247. Retrieved from http://www.ncbi.nlm.nih.gov/pubmed/ 11757569

Choi, A., Kang, T., \& Mun, J. (2016). Biomechanical evaluation of dynamic balance control ability during golf swing. Journal of Medical and Biological Engineering, 36, 430-439. Retrieved from http://link.springer.com/article/10.1007/s40846o16-0141-o

Dancey, C., \& Reidy, J. (2011). Statistics without maths for psychology (5th ed.). London: Prentice Hall.

Deluzio, K. J., \& Astephen, J. L. (2007). Biomechanical features of gait waveform data associated with knee osteoarthritis: An application of principal component analysis. Gait $\mathcal{E}$ Posture, 25(1), 86-93. Retrieved from http://www.ncbi.nlm.nih.gov/pubmed/ 16567093

Donà, G., Preatoni, E., Cobelli, C., Rodano, R., \& Harrison, A. J. (2009). Application of functional principal component analysis in race walking: An emerging methodology. Sports Biomechanics, 8(4), 284-301. Retrieved from http://www.ncbi.nlm.nih.gov/ pubmed/20169759

Exell, T., Gittoes, M. J. R., Irwin, G., \& Kerwin, D. G. (2012). Considerations of force plate transitions on centre of pressure calculation for maximal velocity sprint running. Sports Biomechanics, 11(4), 532-541. Retrieved from http://www.ncbi. nlm.nih.gov/pubmed/23259242.

Hanavan, E. (1964). A mathematical model of the human body (AMRL-TR-64-102, AD-6o8-463). Aerospace Medical Research Laboratories.

Harper, T. E., Roberts, J. R., \& Jones, R. (2005). Driver swing weighting: A worthwhile process? Proceedings of the Institution of Mechanical Engineers, Part B: Journal of Engineering Manufacture, 219(5), 385-393. Retrieved from http://pib. sagepub.com/lookup/doi/10.1243/o95440505X32247

Hellström, J. (2009). Competitive elite golf: A review of the relationships between playing results, technique and physique. Sports Medicine, 39(9), 723-741. Retrieved from http://www. ncbi.nlm.nih.gov/pubmed/19691363
Helwig, N. E., Hong, S., Hsaio-Wecksler, E. T., \& Polk, J. D. (2011). Methods to temporally align gait cycle data. Journal of Biomechanics, 44(3), 561-566. Retrieved from http://www. ncbi.nlm.nih.gov/pubmed/20887992

Hsue, B., Miller, F., \& Su, F.-C. (2009). The dynamic balance of the children with cerebral palsy and typical developing during gait. Part I: Spatial relationship between COM and COP trajec- tories. Gait $\mathcal{E}$ Posture, 29, 465-470. Retrieved from http://www. ncbi.nlm.nih.gov/pubmed/19111469

Jenkins, S. (2008). Weight transfer, golf swing theory and coaching. International Journal of Sports Science and Coaching, 3, 29-51.

Lynn, S. K., Noffal, G. J., Wu, W., \& Vandervoort, A. A. (2012). Using principal components analysis to determine differences in $3 \mathrm{D}$ loading patterns between beginner and collegiate level golfers. Journal of Golf Science, 25-41. Retrieved from http://www.humankinetics.com/acucustom/sitename/Docume nts/ DocumentItem/o4_lynn_IJGS_05_25-41.pdf

Robertson, G., Caldwell, G., Hamill, J., Kamen, G., Whittlesey, S. (2014). Research methods in biomechanics (2nd ed.). Champaign, IL: Human Kinetics.

Smith, A., Roberts, J., Wallace, E., Wah Kong, P., \& Forrester, S. (2015). Golf coaches' perceptions of the key technical swing parameters compared to biomechanical literature. International Journal of Sports Science and Coaching, 10(4), 739-755.

Taliep, M. S., Galal, U., \& Vaughan, C. L. (2007). The position of the head and centre of mass during the front foot off-drive in skilled and less-skilled cricket batsmen. Sports Biomechanics, 6 (3), 345-36o. Retrieved from http://www.ncbi.nlm.nih.gov/ pubmed/17933197

Wallace, E., Grimshaw, P., \& Ashford, R. (1994, July). Discrete pressure profiles of the feet and weight transfer patterns during the golf swing. Paper presented at the meeting of World Scientific Congress of Golf, Scotland.

Welch, C. M., Banks, S., Cook, F. F., \& Draovitch, P. (1995). Hitting a baseball: A biomechanical description. The Journal of Orthopaedic and Sports Physical Therapy, 22(5), 193-201. Retrieved from http://www.ncbi.nlm.nih.gov/pubmed/8580946 Winter, D. (1995). Human balance and posture control during standing and walking. Gait $\mathcal{E}$ Posture, 3(4), 193-214. doi:10.1016/o966-6362(96)82849-9

Wrobel, J., Marclay, S., \& Najafi, B. (2012). Golfing skill level pos- tural control differences: A brief report. Journal of Sports Science and Medicine, 11(3), 452-458. Retrieved from http://www.ncbi. nlm.nih.gov/pmc/articles/PMC3737932/ 


\section{Appendix 1}

Table AI. Golfer marker set including marker names, definitions and anatomical placements.

\begin{tabular}{|c|c|c|}
\hline Marker & Definition & Anatomical placement \\
\hline RFHD & Right front head & Right temple \\
\hline LFHD & Left front head & Left temple \\
\hline RBHD & Right back head & Right back of head \\
\hline LBHD & Left back head & Left back of head \\
\hline RAC & Right acromion & Bony prominence of right shoulder \\
\hline LAC & Left acromion & Bony prominence of left shoulder \\
\hline CLAV & Clavicle & Top of the breast bone \\
\hline STRN & Sternum & Base of breast bone \\
\hline $\mathrm{C}_{7}$ & 7th cervical vertebrae & Prominent vertebrae at base of neck \\
\hline $\mathrm{T}_{2}$ & 2nd thoracic vertebrae & Two vertebrae below $C_{7}$ \\
\hline T8 & 8th thoracic vertebrae & Two vertebrae above T1o \\
\hline T10 & 1oth thoracic vertebrae & Centre of mid-back \\
\hline $\mathrm{L}_{4}$ & 4th lumbar vertebrae & One vertebrae above $\mathrm{L}_{5}$ \\
\hline $\mathrm{L}_{5}$ & $5^{\text {th }}$ lumbar vertebrae & Last vertebrae above sacrum \\
\hline LSHO & Left shoulder & Lateral side of left shoulder at shoulder joint centre level \\
\hline $\mathrm{RSHO}$ & Right shoulder & Lateral side of right shoulder at shoulder joint centre level \\
\hline RBAK & Right back & Right back over right scapula \\
\hline LUP1 & Left upper arm 1 & Posterior side of left upper arm \\
\hline $\mathrm{LUP}_{2}$ & Left upper arm 2 & Lateral side of left upper arm above epicondyle \\
\hline RUP1 & Right upper arm 1 & Posterior side of right upper arm \\
\hline RUP2 & Right upper arm 2 & Lateral side of right upper arm above epicondyle \\
\hline LLELB & Left lateral elbow & Left lateral elbow epicondyle \\
\hline LMELB & Left medial elbow & Left medial elbow epicondyle \\
\hline RLELB & Right lateral elbow & Right lateral elbow epicondyle \\
\hline RMELB & Right medial elbow & Right medial elbow epicondyle \\
\hline LFA & Left forearm & Posterior side of left forearm \\
\hline
\end{tabular}




\begin{tabular}{|c|c|c|}
\hline RFA & Right forearm & Posterior side of right forearm \\
\hline LRAD & Left radius & Left radial epicondyle \\
\hline RRAD & Right radius & Right radial epicondyle \\
\hline LULN & Left ulna & Left ulna epicondyle \\
\hline RULN & Right ulna & Right ulna epicondyle \\
\hline LHA & Left hand & Dorsum of left hand below head of and metacarpal \\
\hline RHA & Right hand & Dorsum of right hand below head of 2 nd metacarpal \\
\hline LASIS & Left anterior superior illiac spine & Bony prominence of the left anterior superior iliac \\
\hline RASIS & Right anterior superior illiac spine & Bony prominence of the right anterior superior iliac \\
\hline LPSIS & Left posterior superior iliac spine & Bony prominence of the left posterior superior iliac \\
\hline RPSIS & Right posterior superior iliac spine & Bony prominence of the right posterior iliac \\
\hline LTH1 & Left thigh 1 & Lateral side of left thigh $\approx 0.1 \mathrm{~m}$ under greater trochanter \\
\hline $\mathrm{LTH} 2$ & Left thigh 2 & $\begin{array}{l}\text { Medial side of left thigh between vastus medialis and rectus } \\
\text { femoris }\end{array}$ \\
\hline $\mathrm{LTH}_{3}$ & Left thigh 3 & Left vastus lateralis tendon \\
\hline RTH1 & Right thigh 1 & Lateral side of right thigh $\approx 0.1 \mathrm{~m}$ under greater trochanter \\
\hline $\mathrm{RTH} 2$ & Right thigh 2 & $\begin{array}{l}\text { Medial side of right thigh between vastus medialis and rectus } \\
\text { femoris }\end{array}$ \\
\hline $\mathrm{RTH}_{3}$ & Right thigh 3 & Right vastus lateralis tendon \\
\hline LLK & Left lateral knee & Left lateral knee epicondyle \\
\hline RLK & Right lateral knee & Right lateral knee epicondyle \\
\hline LMK & Left medial knee & Left medial knee epicondyle \\
\hline RMK & Right medial knee & Right medial knee epicondyle \\
\hline LSK1 & Left shank 1 & Lateral side of left shank \\
\hline $\mathrm{LSK}_{2}$ & Left shank 2 & Lateral side of left shank \\
\hline $\mathrm{LSK}_{3}$ & Left shank 3 & Lateral side of left shank \\
\hline $\mathrm{LSK}_{4}$ & Left shank 4 & Lateral side of left shank \\
\hline RSK1 & Right shank 1 & Lateral side of right shank \\
\hline RSK2 & Right shank 2 & Anterior side of right shank \\
\hline $\mathrm{RSK}_{3}$ & Right shank 1 & Lateral side of right shank \\
\hline $\mathrm{RSK}_{4}$ & Right shank 1 & Lateral side of right shank \\
\hline LLA & Left lateral ankle & Left lateral malleolus \\
\hline LMA & Left medial ankle & Left medial malleolus \\
\hline RLA & Right lateral ankle & Right lateral malleolus \\
\hline RMA & Right medial ankle & Right medial malleolus \\
\hline LTOE & Left toe & Dorsum of left foot below and metatarsal \\
\hline RTOE & Right toe & Dorsum of right foot below 2 nd metatarsal \\
\hline RHEEL & Right heel & Posterior side of right heel \\
\hline LHEEL & Left heel & Posterior side of left heel \\
\hline
\end{tabular}

